\title{
Reliability-Based Design for the Flexural Capacity of Fiber Reinforced Concrete Slabs on Ground
}

\author{
Raghad Awad $^{1}$, Samer Barakat ${ }^{1}$, Salah Altoubat ${ }^{1}$, Moussa Leblouba1 \\ ${ }^{1}$ Department of Civil and Environmental Engineering, College of Engineering, University of Sharjah \\ Sharjah, United Arab Emirates \\ raawad@sharjah.ac.ae; sbarakat@sharjah.ac.ae \\ saltoubat@sharjah.ac.ae; mleblouba@sharjah.ac.ae
}

\begin{abstract}
The contribution of fibers in enhancing the mechanical behavior and providing a post-crack residual capacity of the concrete sections have widely been investigated and design approaches of fiber reinforced concrete (FRC) are established. These design approaches are usually uncertain and associated with inherent variability and modeling errors in which should be accounted for when designing reliable structures. The addition of fibers has further increased the range of uncertainties resulting in inconsistent levels of reliability for FRC structures when compared with those established for traditional reinforced concrete structures. To this end, this paper conducts a reliability-based analysis of the ultimate limit state (ULS) of the fiber reinforced concrete slabs (FRCS) on ground under flexural loading. The ULS is formulated based on the procedure adopted in the ACI 360R regarding the calculation of the post-crack moment capacity of fiber reinforced concrete slabs (FRCS) on ground under flexural loading. To ensure that the design procedure provides acceptable reliability levels, experimental results collected from previous studies were used in the statistical calibration. MonteCarlo simulation was adapted to generate an array of random variables knowing their statistical parameters and distributions. Reduction factors for the flexural strength of FRC slabs corresponding to the load factors specified in the design codes were calculated and certain values are proposed to achieve target reliability levels.
\end{abstract}

Keywords: Reliability, reduction factor, variation, distribution, fiber reinforced concrete, fibers, ground slabs.

\section{Introduction}

One of the major issues of attaining high strength concrete in conventional concrete is the resulting brittleness of the composite, which might cause deleterious damage of the structural members, fibers are added to overcome such phenomenon. Many research studies have been carried out to investigate the mechanical properties of fiber reinforced composites in the last half-century. Although many design equations and analytical models were obtained from these studies to describe the behavior of FRC slabs, reliable design codes are still missing and the behavior of FRC slabs is still a research problem that requires more investigation.

No doubt that the availability of reliable standards will guide the engineers in a more sustainable manner. Rao et al. [1] performed a reliability analysis of steel fiber reinforced concrete beams subjected to flexural loading using first-order second moment (FOSM) method and compared the results with conventional reinforced concrete beams. The researcher concluded that an increase of $72 \%$ in the reliability index value in SFRC beams compared with conventional reinforced beams. Pukl et al. [2] investigated the available safety formats of two fiber reinforced concrete members; prismatic specimens under fourpoint bending test and tunnel segments under flexural loading. The investigation includes four safety design approaches available in the fib Model Code 2010, namely, full probabilistic analysis, Estimate of Coefficient of Variation (ECOV), EN 1992-2 method and finally Partial Safety Factors (PSF). More realistic resistance estimation of the fiber composites was observed in both PSF and EN 1992-2 design approaches than in the full probabilistic analysis or ECOV. This can be attributed that the latter two methods don't account for the variability and uncertainties of FRC material properties when evaluating the structural performance.

More recently, Siddiqui et al. [3] carried out a probabilistic analysis using Monte-Carlo simulation on hybrid fiber reinforced concrete slabs subjected to projectile impact by varying the proportion of hooked-end steel, polypropylene and kevlar fibers. He found that to achieve target reliability of 3 under impact loading, the steel fiber percentage should increase to $1.8 \%$. 
The assurance of reliable and safe performance of a structure is achieved through probabilistic analyses taking into consideration the inherited uncertainties of the variable. Two approaches can be adapted when designing for reliability, namely; the traditional approach using safety factors and the use of the Load and Resistance Factor Design (LRFD) format where separate factors for the load and resistance are calibrated to reflect the uncertainties. ACI 360R [4] lists several safety factors for different types of slabs loading typically ranged from 1.4 to 2 . However, The LRFD procedure is widely implemented among researchers, in which a target reliability level is set to be met using load and resistance factors. Design guides adopted for FRC members, load and resistance factors similar to those used for traditional concrete. These recommended factors may, however, over/underestimate a target reliability index. The aim of calibrating the strength reduction factor is to achieve desirable and consistent reliability for FRC members.

\section{Reliability Analysis: LRFD Calibration of Limit State Equation}

A rule of thumb when designing structural elements, the reduced nominal resistance of the fiber reinforced concrete section should be greater than the factored applied load, as illustrated in equation (1).

$$
\Phi R_{n} \geq \sum_{i=1}^{j} \gamma_{\mathrm{i}} Q_{\text {in }}
$$

Where $R_{n}$ is the nominal resistance for a particular limit state, $\Phi$ is the resistance reduction factor, $Q_{\text {in }}$ is the nominal load applied and $\gamma_{\mathrm{i}}$ is the associated load factor.

The ultimate limit state function of structural members can be defined as:

$$
g_{m}=R_{m}-Q_{m}
$$

Where $g_{m}$ is a random variable representing the margin of safety, $R_{m}$ and $Q_{m}$ are random measured (actual) resistance and load values, respectively. Both load and resistance involve degree of uncertainties. Usually, nominal (predicted) values of resistance and load used in limit state design equations, vary from measured values for a limit state for a typical structure. If the value of $g_{m} \geq 0$, the structure is safe; otherwise, failure occurs.

For this study, the resistance capacity of FRC slabs, $R_{m}$, is calculated using simplified equations adapted by ACI 360R (guides for the design and construction of ground floors) [4] based on the work of Meyerhof [5], who assumed that the slab is rigid plastic resting on an elastic subgrade considering yield line method for the design of FRC slabs on ground and redistribution of moments. Three separate cases of loading were proposed, differentiated based on the location of the load with the slab. In Meyerhof approach, the contribution of fibers in enhancing the carrying capacity of slabs was accounted for by introducing an $R_{e, 3}$ ratio obtained from four-point flexural bending test on prismatic specimens according to ASTM C1609 [6] and JCI-SF4 [7]. The reliability analysis conducted in this paper considers only centrally loaded slabs since limited number of full-scale tests of FRCS under edge and corner loading are available. The estimation of the ultimate load-carrying capacity of FRCS are given in equations (3)-(6):

$$
\begin{gathered}
P_{o}=6\left[1+\frac{2 a}{l}\right] M_{0} \quad\left(\text { for load } P_{o}\right. \text { in center of the panel) } \\
L=\sqrt[4]{\frac{E h^{3}}{12\left(1-v^{2}\right) k}} \\
M_{0}=\left[1+\frac{R_{e, 3}}{100}\right] \times f_{r} \times \frac{b h^{2}}{6} \quad \text { (for Fiber Reinforced Concrete) }
\end{gathered}
$$




$$
R_{e, 3}=\frac{f_{e, 3}}{f_{r}}
$$

Where:

$P_{o}=$ Ultimate load capacity of the slab $\mathrm{kN}$.

$a=$ Radius of a circle with an area equal to that of the post base plate $\mathrm{mm}$.

$M_{0}=$ Limit moment of slab resistance N-mm.

$L=$ Radius of relative stiffness (unitless).

$\mathrm{E}=$ Young Modulus of FRC concrete MPa.

$v=$ FRC Poisson's ratio (unitless).

$k=$ subgrade reaction modulus $\mathrm{N} / \mathrm{mm}^{3}$.

$R_{e, 3}=$ Equivalent flexural strength ratio at $3 \mathrm{~mm}(\%)$ obtained from four point bending test on prisms.

$f_{e, 3}=$ Equivalent flexural strength at $3 \mathrm{~mm}$.

$b=$ Unit width of slab mm.

$h=$ Slab thickness mm.

$f_{r}=$ Concrete flexural strength MPa.

\section{1. Statistical Parameters of Resistance}

As mentioned earlier, load and resistance involve degree of uncertainties; the resistance of the structural member computed depends on geometric and mechanical properties, which also include statistical variations. Generally, three sources of uncertainty can affect the variability of the resistance; material variability $\left(\psi_{M}\right)$ reflecting the variability in the mechanical characteristic in the material such as strength, fabrications variability $\left(\psi_{F}\right)$ including variation in dimensions and geometry of the considered structural elements; and lastly analysis or professional factor $\left(\psi_{P}\right)$, which will reflect the model prediction accuracy. All these variables are treated as random variables in the analysis, in which bias factors and coefficients of variation $(\mathrm{COV}) \mathrm{s}$ should be determined for each variable.

$$
\begin{gathered}
R=R_{n} \cdot \psi_{M} \cdot \psi_{F} \cdot \psi_{P} \\
\lambda_{R}=\lambda_{M F} \cdot \lambda_{P} \\
V_{R}=\sqrt{V_{M F}^{2}+V_{p}^{2}}
\end{gathered}
$$

Where $\lambda_{M F}$ and $\mathrm{V}_{M F}$ are the bias and COV of the combined material and fabrication; and $\lambda_{P}$ and $V_{P}$ are bias and COV of the professional (analytical) factor, respectively. The ratio of the measured experimentally to predicted value is called "bias".

Adding steel fibers in the matrix has a minor influence on, for instance, the compressive strength, the Poisson's ratio, modulus of elasticity and porosity [8]. Available Studies proved that the variation of the post-peak mechanical properties of the SFRC is expected to be higher than plain concrete ones, due to the randomness of the quantity and orientation of steel fibers in the SFRC specimen. Variation in FRC physical properties is mainly by different factors including fiber dosage and dimensions and specimen size. Typically, the higher the dosage, the less variation observed as a more uniform distribution of fibers across the concrete section [9].Regarding the uncertainties in the fabrication and material parameters, the statistical parameters of the related random variables adopted in this study were collected from the literature and summarized in Table 1.

The uncertainty in the analytical model used for predicting the resistance can be quantified by comparing the experimental results with the model results. Thus, the bias of the professional factor $\lambda_{P}$ can be calculated as the mean of the 
ratio of experimental flexural capacity to the one predicted by design equations. Indeed, the magnitude of bias values denoted as $\lambda_{P}$, will reflect the model accuracy [10].

Twenty-eight slabs were collected from the available literature [11]-[18] and analyzed. Fig. 1 plotted the predicted capacity using equation (3) adapted by ACI 360R versus the ultimate experimental capacity of FRC slabs on ground under central loading. It is clear from Fig. 1 that all the experimental results are below the equality line which indicates that the design model provides, for the collected data, conservative results when compared with the experimental data. The bias of the professional factor $\lambda_{P}$ calculated as the mean of the ratio of experimental flexural capacity to the one predicted by design equations $P_{\text {exp }} / P_{\text {pred }}$. Thus, a value of $\lambda_{P}$ greater than one indicates that the design equation underestimates the actual resistance value. In our case, a ratio of $\lambda_{P}$ was found to be equal to 1.66 with a COV equals to 0.28 . After calculating the resistance parameters, the resistance bias values were plotted against their probabilities to evaluate the best fit. The data can be fitted into both lognormal and generalized extreme value distribution. Both distributions were accepted when AndersonDarling and Kolmogorov-Smirnov goodness of fit tests were performed. However, the lognormal distribution was considered for the purpose of the analysis in this paper. Table 2. Lists the statistical parameters of the resistance.

\section{2. Statistical Parameters of Load}

It should be noted that pavements are typically subjected to various types of loading, including dead and vehicular live loads [4]. The statistical parameters of the load random variable component were taken from Ellingwood [19], who found that the live load values follow a Gumbel distribution with load bias and COV equal to 1.0 and 0.25 , respectively. However, these statistical values agree with what was stated in [20] but with a slightly smaller COV equal to 0.18.

As for the applied load factor, a minimum value of $\gamma=1.2$ is recommended by [21] when designing the ultimate state of FRCS on ground. While, a load factor, $\gamma_{\mathrm{LL}}$ of 1.75 corresponds to the vehicular live loads is adopted by standard AASHTO LRFD [22] design specifications for concrete pavements and bridges.

Table 1: Material and fabrication statistical parameters.

\begin{tabular}{|c|c|c|c|c|}
\hline Parameter & $\begin{array}{c}\text { Probability } \\
\text { Distribution } \\
\text { type }\end{array}$ & Bias & COV & Ref. \\
\hline Slab thickness, $\mathbf{h}_{\mathbf{s}}$ & Normal & 1.00 & 0.060 & {$[12]$} \\
\hline Beam width, b & Normal & 1.01 & 0.040 & {$[12]$} \\
\hline $\begin{array}{l}\text { Equivalent flexural strength, } \\
\qquad \boldsymbol{f}_{\boldsymbol{e}, \mathbf{3}}\end{array}$ & Normal & $1.00^{\mathrm{b}}$ & 0.240 & $\begin{array}{c}{[24][25]} \\
{[26]}\end{array}$ \\
\hline Modulus of Rupture, $\boldsymbol{f}_{\boldsymbol{r}}$ & Normal & 1.00 & 0.110 & $\begin{array}{c}{[27]} \\
{[28][26]}\end{array}$ \\
\hline Modulus of Elasticity, $\mathbf{E}$ & Normal & 1.01 & 0.109 & $\begin{array}{l}{[29][30]} \\
\quad[31]\end{array}$ \\
\hline Poisons ratio, $v$ & Normal & 1.00 & 0.071 & {$[29][30]$} \\
\hline Subgrade modulus, $\mathbf{k}$ & Normal & $1.01^{\mathrm{a}}$ & 0.050 & {$[32]$} \\
\hline Live load, $\mathbf{L L}$ & $\begin{array}{l}\text { Extreme } \\
\text { Type I }\end{array}$ & 1.00 & 0.250 & [19] \\
\hline \multicolumn{5}{|c|}{$\begin{array}{l}\text { a- Assumed, b- The test method has no bias since the properties determined can only be } \\
\text { defined in terms of this test method [6] }\end{array}$} \\
\hline
\end{tabular}




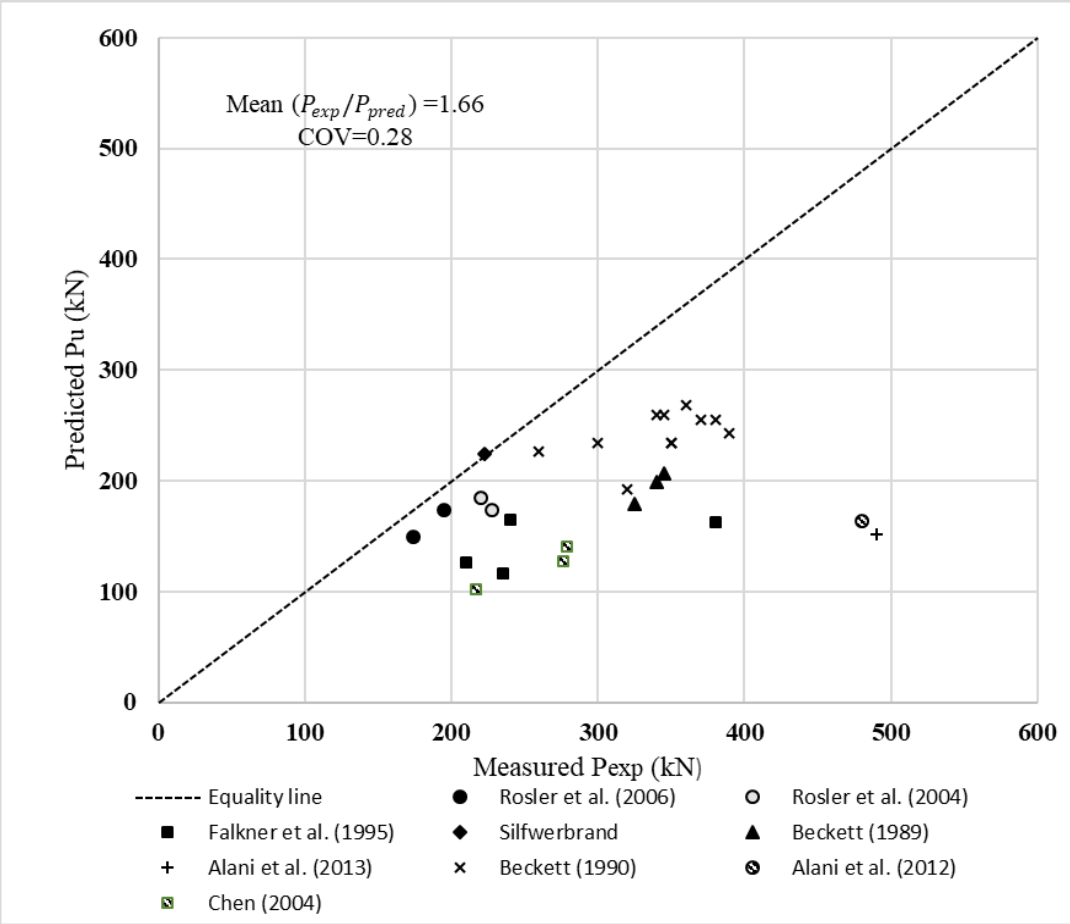

Table 2: Resistance parameters.

\begin{tabular}{c|c}
\hline Factors & Value \\
\hline$\lambda_{\boldsymbol{P}}$ & 1.663 \\
\hline $\boldsymbol{V}_{\boldsymbol{P}}$ & 0.275 \\
\hline $\boldsymbol{\lambda}_{\boldsymbol{M F}}$ & 1.016 \\
\hline $\boldsymbol{V}_{\boldsymbol{M F}}$ & 0.166 \\
\hline $\boldsymbol{\lambda}_{\boldsymbol{R}}$ & 1.690 \\
\hline $\boldsymbol{V}_{\boldsymbol{R}}$ & 0.325 \\
\hline
\end{tabular}

Fig.1: Experimental versus predicted load carrying capacity at failure.

However, Technical report 34 [23] used in ground-supported floors a material partial safety factor of 1.5 for fiber reinforced concrete. TR 34 also adapted load factors of 1.2 and 1.6 that correspond to defined racking and dynamic loads, respectively. To account for all cases, a load factor range between 1.2 to 1.75 was adapted in the LRFD calibration procedure.

\section{3. Selection of Target Reliability Index}

Depending on the type, use of the structure, and the situation considered in the design, a target reliability, expressed in terms of the accepted minimum reliability index or the accepted maximum failure probability [33] is specified. Generally, the structural components are considered safe when their reliability indices are 3 or above following the ACI 318 building code requirements. Specifically, a target reliability index level of $\beta=3.5$ is needed for plant cast slabs and $\beta=2.5$ for cast in place slabs [20].

The final step is the calculation of strength reduction factor, $\Phi$, corresponding to a load factor and reliability level, $\beta$ as per ACI 318. A Strength reduction factor of 0.8 for bending for FRC was recommended by Bekaert [34]. However, ACI $544.4 \mathrm{R}$ [35] recommends adjustments of the strength reduction factors for fiber reinforced members, $\Phi_{\mathrm{FRC}}$, based on the member type and failure mode before using when designing these members.

\section{Reliability Analysis Results}

\section{1. Calibration procedure using Monte-Carlo (MC) simulation}

By knowing the statistical parameters and the corresponding distribution for the resistance and load bias values and after accounting for the uncertainties inherited in the analytical prediction as well as material and fabrication uncertainties, the limit state function was formulated and the corresponding probability of failure was calculated using Monte-Carlo simulation with the predefined parameters and distributions. In the load and resistance factor design calibration procedure, the 
distributions were considered as Gumbel distribution (Type-I Extreme Value) of the load bias along with lognormal distribution of the resistance bias. The strength reduction factor was calculated by varying the target reliability level and load factor between 2.5 to 3.5 and 1.2 to 1.75 as mentioned earlier, respectively. Furthermore, two cases of the load statistics were taking into consideration for each load factor and target reliability level. The outcomes of the resistance $\Phi$ for different target reliability levels are plotted in Fig.2.

\section{2. Discussion of results}

Fig. 2 clearly illustrates that for a target reliability index of 3.5, specified for plant cast slabs, the values of the strength reduction factor, $\Phi$, corresponding to load factor between 1.2 to 1.75 ranged from 0.5 to 0.8 . While more conservative values of $\Phi$, between 0.7 to 1.1 , were found to achieve lower target reliability levels of $\beta=2.5$. A strength reduction factor equals or greater than one assures a reliable structural performance in which resistance reduction isn't needed. Therefore, the outcomes of Fig.2 indicate that the design approach adopted by ACI 360R for the design of FRC slabs on ground under ULS is reliable when a minimum load factor of approximately 1.7 is considered in the ultimate design.

To provide the minimum reliability levels of 2.5 specified by the design codes for concrete slabs, A reduction factor of 0.8 and 0.9 is recommended when the applied load is factored up to 1.35 and 1.5 times, respectively. However, by increasing the load factor up to 1.75 and decreasing the reduction factor to reach 0.7 the reliability levels can be increased up to 3.5 . Fig. 2 also illustrates the effect of variation in the load statistics on the outcomes of the calibration procedure. As expected, lower strength reduction was needed for lower load COV to achieve the same reliability index.

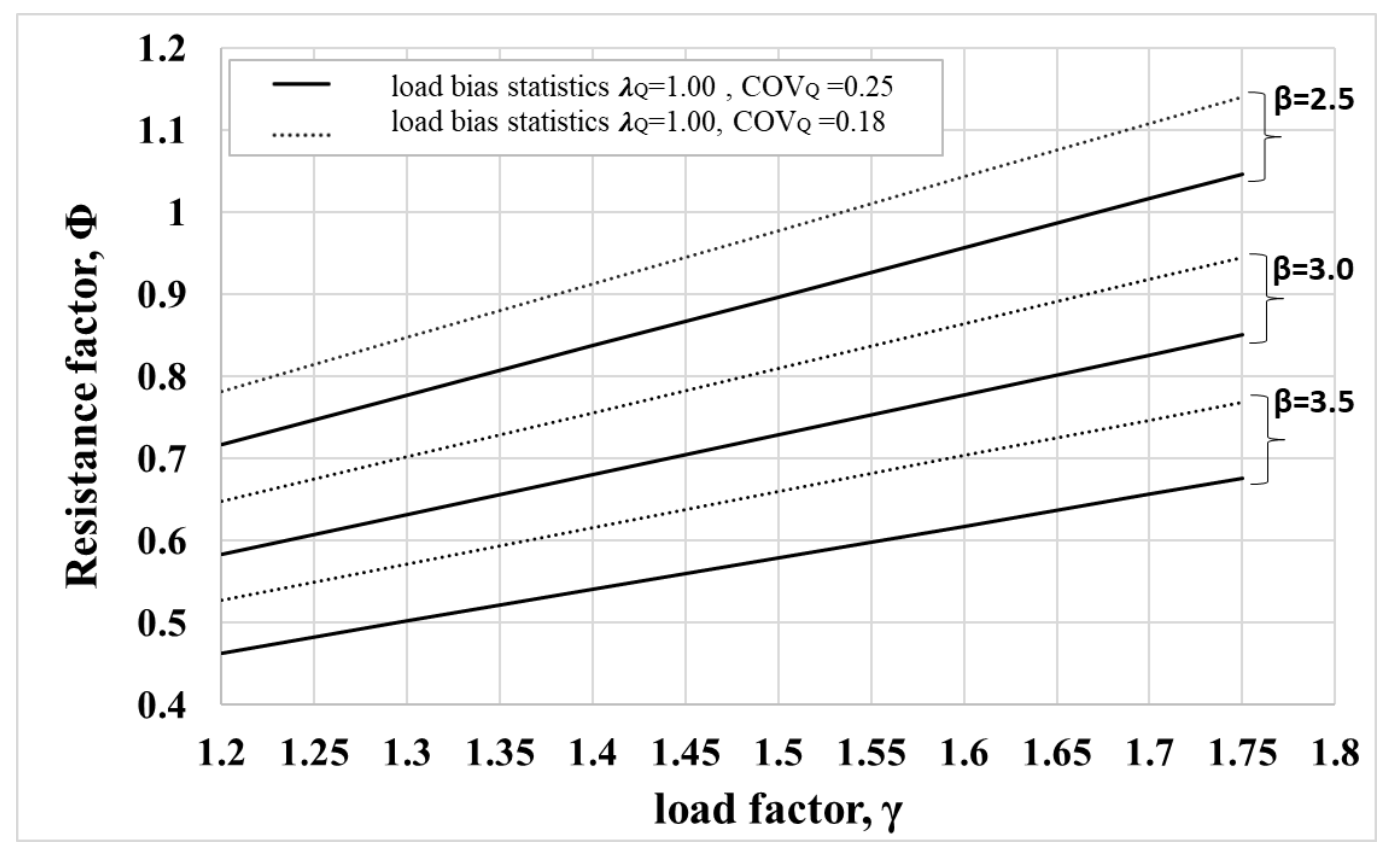

Fig. 2: Outcomes of the resistance factor, $\Phi$ for different target reliability levels.

\section{Conclusion}

From the LRFD calibration and validation analysis conducted in this paper, it can be concluded that:

1. When adapting the typically used reduction factor for conventional reinforced concrete slabs under flexural loading (i.e. $\Phi=0.9$ ), attention should be paid to the minimum load factor used; a minimum load factor of approximately 1.5 is necessary for SFRC slabs to achieve the same required reliability levels of conventional concrete slabs (i.e. $\beta$ $=2.5$ ). 
2. Designing for the ultimate limit state for SFRC slabs on ground considering a load factor of 1.7 can assure that the design approach adopted by ACI 360R under flexural loading is safe and resistance reduction isn't needed. However, designing using lower load factors necessitates the need of appropriate reduction factors to meet the required reliability. Therefore, if resistance reduction is not accounted for in the design, vehicular live load should be considered as one of the applied loads when designing SFRC slabs on grounds even if they are not meant for that purpose.

3. To achieve the minimum accepted reliability levels specified for slabs; strength reduction factor of 0.7 is recommended when a load factor of 1.2 is used for the static load in the ultimate design. While a strength reduction factor of 0.95 is recommended along with a load factor of 1.6 to account for dynamic loads. However, a target reliability index of $\beta=3$ requires more conservative values of $\Phi$, approximately 0.6 to 0.8 corresponding to load factors of 1.2 and 1.6, respectively.

\section{References}

[1] T. D. G. Rao, M. Andal, S. Sahu, and P. C. F. Asce, "Probabilistic Assessment on Flexural Strength of Steel Fiber Reinforced Concrete Members," Int. J. Eng. Res. Gen. Sci. Vol., vol. 3, no. 1, pp. 520-527, 2015.

[2] R. Pukl, T. Sajdlová, J. Červenka, and V. Červenka, "Performance of fibre reinforced concrete structures - Modelling of damage and reliability," Key Engineering Materials, vol. 711, no. September, pp. 690-697, 2016.

[3] N. A. Siddiqui, Y. A. AL-Salloum, T. H. Almusallam, A. A. Abadel, and H. Abbas, "Reliability Assessment of HFRC Slabs Against Projectile Impact," Int. J. Concr. Struct. Mater., vol. 12, no. 1, p. 58, 2018.

[4] ACI Committee 360, Guide to Design of Slabs-on-Ground (ACI 360R-10 ), Am. Concr. Institute, Farmingt. Hills, MI, pp. 1-72, 2010.

[5] G. G. Meyerhof, "Load Carrying Capacity of Concrete Pavements," Journal of the Soil Mechanics and Foundations Division Proceedings of the American Society of Civil Engineers, pp. 89-116, 1962.

[6] ASTM C1609 / C1609M-19, "Standard Test Method for Flexural Performance of Fiber-Reinforced Concrete (Using Beam With Third-Point Loading), " ASTM International, West Conshohocken, PA, 2019,

[7] JCI, "Method of Tests for Flexural Strength and Flexural Toughness of Fiber Reinforced Concrete," JCI Standard SF-4, Japan Concrete Institute Standards for Test Method of Fiber Reinforced Concrete, Japan 1984.

[8] G. L. Vondran, "Applications of steel fiber reinforced concrete. Concrete international," Concr. Int., vol. 13, no. 11, pp. 44-49, 1991.

[9] B. Parmentier, L. Vandewalle, and F. Van Rickstal, "Evaluation of the scatter of the postpeak behaviour of fibre reinforced concrete in bending: A step towards reliability," 7th RILEM Symp. Fibre Reinf. Concr. BEFIB, no. 1, pp. 133-143, 2008.

[10] K.K. Phoon, J. Ching. Risk and Reliability in Geotechnical Engineering. Boca Raton: CRC Press, 2015.

[11] J. R. Roesler, S. A. Altoubat, D. A. Lange, K. A. Rieder, and G. R. Ulreich, "Effect of synthetic fibers on structural behavior of concrete slabs-on-ground," ACI Mater. J., vol. 103, no. 1, pp. 3-10, 2006.

[12] J. R. Roesler, D. A. Lange, S. A. Altoubat, K. A. Rieder, and G. R. Ulreich, "Fracture of plain and fiber-reinforced concrete slabs under monotonic loading," J. Mater. Civ. Eng., vol. 16, no. 5, pp. 452-460, 2004.

[13] H. V Dwarakanath and T. S. Nagaraj, "Comparative Study of Predictions of Flexural Strength of Steel Fiber Concrete," ACI Struct. J., vol. 88, no.6, pp. 714-720, 1992.

[14] D. Beckett and J. Humphreys, "Comparative Tests on Plain, Fabric Reinforced, and Steel Fiber Reinforced Concrete Ground Slabs," Thames Polytechnic School of Civil Engineering, Dartford, U.K., 1989.

[15] A. M. Alani and D. Beckett, "Mechanical properties of a large scale synthetic fibre reinforced concrete ground slab," Constr. Build. Mater., vol. 41, pp. 335-344, 2013.

[16] D. Beckett, "Comparative tests on plain, fabric reinforced and steel fibre reinforced concrete ground slabs," Concrete, vol. 24, no. 3, pp. 43-45, 1990.

[17] A. Alani, D. Beckett, and F. Khosrowshahi, "Mechanical behaviour of a steel fibre reinforced concrete ground slab," Mag. Concr. Res., vol. 64, no. 7, pp. 593-604, 2012. 
[18] S. Chen, "Strength of steel fibre reinforced concrete ground slabs," Proc. Inst. Civ. Eng. Struct. Build., vol. 157, no. 2, pp. 157-163, 2004.

[19] B. R. Ellingwood, "Probability-based Codified Design: Past Accomplishments and Future Challenges," Elsevier Sci. Struct. Saf., vol. 13, no. 3, pp. 159-176, 1994.

[20] Szerszen, M. M., \& A. S. Nowak, "Calibration of design code for buildings (ACI 318): Part 2-Reliability analysis and resistance factors," ACI Struct. J., vol. 100, no. 3, pp. 383-391, 2003.

[21] Indian Road Congress. Guidelines For Design and Construction of Fibre Reinforced Concrete Pavements, IRC SP 46, India Offset Press, New Delhi, India, 2013.

[22] AASHTO, "LRFD Bridge Design Specifications," 8th Ed. Am. Assoc. State Highw. Transp. Off. Washington, DC, p. 1781, 2017.

[23] Technical Report (TR) 34, Concrete industrial ground floors: A guide to design and construction, 4th Edition, Concrete Society, Crowthorne, UK, 2013.

[24] S. W. Dean, E. S. Bernard, and G. G. Xu, "Statistical Distribution of Fiber-Reinforced Concrete Beam Test Data," J. ASTM Int., vol. 4, no. 3, pp. 1-12, 2007.

[25] A. N. Lambrechts, "The variation of steel fibre concrete characteristics. Study on toughness results 2002-2003." International Workshop on advances in Fiber Reinforced Concrete, 2004.

[26] A. Conforti, G. A. Plizzari, and G. Tiberti, "Comparing test methods for the mechanical characterization of fiber reinforced concrete," Struct. Concr., vol. 19, no. 3, pp. 656-669, 2018.

[27] M. Mastali and A. Dalvand, "The impact resistance and mechanical properties of self-compacting concrete reinforced with recycled CFRP pieces," Compos. Part B Eng., vol. 92, pp. 360-376, 2016.

[28] M. Fakharifar, A. Dalvand, M. Arezoumandi, M. K. Sharbatdar, G. Chen, and A. Kheyroddin, "Mechanical properties of high performance fiber reinforced cementitious composites," Constr. Build. Mater., vol. 71, pp. 510-520, 2014.

[29] X. Gu, L. Hong, Z. Wang, and F. Lin, "A modified rigid-body-spring concrete model for prediction of initial defects and aggregates distribution effect on behavior of concrete," Comput. Mater. Sci., vol. 77, pp. 355-365, 2013.

[30] J. Thomas and A. Ramaswamy, "Mechanical Properties of Steel Fiber-Reinforced Concrete," J. Mater. Civ. Eng., vol. 19, no. 5, pp. 385-392, 2007.

[31] A. Sivakumar and M. Santhanam, "Mechanical properties of high strength concrete reinforced with metallic and nonmetallic fibres," Cem. Concr. Compos., vol. 29, no. 8, pp. 603-608, 2007.

[32] B. Kuriakose, A. Krishnan, G. R. Dodagoudar, and B. Nageswara Rao, "Probabilistic settlement analysis of rafts using first order reliability method," Int. J. Earth Sci. Eng., vol. 9, no. 1, 2016.

[33] JCSS - Joint Committee on Structural Safety, "Part 1: Basis of Design" in Probabilistic Model Code, The Netherlands 2001.

[34] IAPMO - International Association of Plumbing And Mechanical Officials, "Evaluation Report", no. 400, Ontario, CA, USA, 2019.

[35] ACI Committee 544, Guide to Design with Fiber-Reinforced Concrete (ACI 544.4R), in American Concrete Institute: Farmington Hills, MI, USA, 2018. 